\author{
수리조선 작업장에서의 공기중 석면 노출에 관한 연구 \\ 심상효* 정희태** • 송기민**** 김윤신* · 강용선***** \\ *한양대학교병원 산업의학과, **한국의료경영정보연구원 \\ ****법무법인 정세, *****산재의료관리원 창원병원 \\ (2008. 6. 26. 접수/2008. 7. 26. 수정/2008. 8. 9. 채택)

\section{A Study on Exposure to Asbestos a Shipbuilding Repair Business} \\ Sang Hyo Sim* • Hee Tae Chung** • Ki Min Song*** • \\ Yoon Shin Kim* . Yong Seon Kang***** \\ *Department of Occupational and Environmental Medicine, Hanyang University Medical Center \\ **Korea Healthcare Management Research Institute \\ *** Law Firm Jeong Se \\ ****Changwon General Hospital Workers Accident Medical Corporation \\ (Received June 26, 2008/Revised July 26, 2008/Accepted August 9, 2008)
}

\begin{abstract}
This paper aims to provide basic data for work environment control, prevention of worker exposure to asbestos and improvement of air quality to protect workers 'health after measuring the level of airborne asbestos and workers' exposure in a shipbuilding repair businesses. For this study, a total of 27 samples were collected from 27 workers who had been exposed to asbestos during engine, piping, boiler and other manufacturing processes in 'A' Shipbuilding Repair Company in Gyeongnam. This research was conducted from Oct. 1 to 30, 2007 and had the following results: The target group ( 27 workers) consisted of all men with an average age of 35.9 years and 6.6 years of work on average. Among them, fifteen $15(55.6 \%)$ were smokers. In terms of their duties at work, there were 12 plumbing repair engineers (44.4\%), 8 boiler repair engineers $(29.6 \%)$ and 7 engine engineers $(25.9 \%)$. The geometric mean concentration of airborne asbestos was $0.004 \mathrm{f} / \mathrm{cc}$. A total of 4 samples exceeded the exposure limit. In particular, three exceeded the legal limit by more than double, which means that some workers have been highly exposed to asbestos. In terms of the concentration of asbestos fibres by work process, plumbing repair was the highest $(0.0071 \mathrm{f} / \mathrm{cc}(0.001 \sim 0.57 \mathrm{f} / \mathrm{cc}))$ while boiler was the lowest $(0.0015 \mathrm{f} / \mathrm{cc}(0.001 \sim 0.007 \mathrm{f} / \mathrm{cc}))$. Based on this study, proper action needs to be taken as soon as possible to protect workers from the threat of asbestos.
\end{abstract}

Key words : Shipbuilding repair, Asbestos

\section{I. 서 론}

조선산업의 기반은 1950 년대의 사회적 혼란기를 거 쳐, 1960년대 조선산업 육성정책을 통해, 단일 조선소 별 건조능력에 있어서도 세계 $1,2,3$ 위가 모두 우리나라 조선업체들이며,이러한 양적 성장뿐만 아니라, 기술경 쟁력, 생산성향상, 생산자동화 등 질적인 면에서도 크

${ }^{\dagger}$ Corresponding author: Changwon General Hospital, Workers Accident Medical Corporation

Tel: 82-55-282-5110, Fax: 82-55-280-7664

E-mail : kys3977@hanamail.net
게 성장하였다. ${ }^{1}$

조선수리산업이란 선박의 개조, 보수, 정비 등을 수행 하는 조선산업의 세부업종 중 하나이며, 수리조선 산업 은 기술 및 노동집약적 산업으로 기계, 철강, 전기전자, 화학 등 연관산업에 대한 생산 유발효과 및 고용효과 가 높은 산업이며,2) 1980 년대 말 이후에는 선박을 건 조하거나 수리할 때 석면의 사용 감소로 노출량이 적 을 수 있으나, 이미 오래전에 석면을 사용하여 건조된 배를 수리하는 경우에는 석면에 상당량 노출된다. 또한 석박의 기관 및 배관의 단열에 위해서 여전히 석면포 를 사용하고 있는 실정이다. ${ }^{3)}$ 
석면에 가장 많이 노출될 것으로 예상되는 산업으로 는 석면 채굴업, 석면방직품 제조, 석면 단열재 제조, 건축자재 제조와 브레이크라이닝 등 석면을 이용한 제 조업이 있으며, 조선업의 경우는 선박의 배관, 단열을 위한 취외, 제작, 취부작업과 선체의 제작 등에서 석면 에 노출될 수 있다. 특히 수리조선업은 선박의 수리 및 해체과정에서 방열, 단열재로 사용했던 석면의 제거, 교 체작업을 통해서 석면에 노출될 가능성이 매우 높다. ${ }^{4)}$ 우리나라의 경우 1960년대부터 석면이 사용되어 왔 으며, 1976년 수입량은 74,000톤에서 1995년 88,700톤 까지 꾸준히 증가하였으나, 석면으로 인한 피해사례가 늘면서 1990년 이후부터 석면의 수입 규제가 시작되어 2000년 28,900톤, 2003년 22,000톤, 2005년 6,477톤으 로 해가 거듭될수록 수입량이 급격히 감소하고 있는 추 세이다. ${ }^{5,6)}$

석면에 장기간 노출되면 약 15 30년의 잠복기를 거 쳐 호흡기계 질환인 석면폐증(asbestosis), 폐암(lung cancer), 악성중피종(mesothelioma)을 유발하며, 장관계 의 암과 인후두암, 유방암, 난소암, 신장암, 췌장암, 부 고환암, 임파선암, 원형무기폐, 흥수나 흥막염을 유발 한다. ${ }^{7,8)}$

현재 전 세계에서 1 억 2,500 만 근로자가 석면에 노 출되어 있고, 매년 약 9 만명의 근로자가 석면 노출과 관련된 석면폐증, 폐암, 악성중피종 등의 질병으로 사 망하는 것으로 추정되며,9) 우리나라에서도 2000년부터 2007 년까지 총 68 명의 석면 관련 직업병 환자가 발생 하였고 2005 년 이후에 발생한 환자가 41 명 (60.29\%)으 로 1970 1980년대 집중 수입량과 잠복기를 고려할 때 향후 직업병 발생이 급격히 증가할 가능성이 있다. ${ }^{10)}$

외국의 경우 일본은 2004 년 10 월부터 청석면과 갈 석면 외의 기타 석면을 사용하는 건설자재 및 자동차 부품 등 특정 석면함유 제품의 제조, 수입, 판매 및 사용까지 제한함으로써 모든 종류의 석면사용을 금지 하였다. ${ }^{11)}$

우리나라는 2007년부터는 건축자재, 마찰재에 대한 신규 제조 및 수입을 금지하였으며, 2008년 1월에는 $0.1 \%$ 초과하여 함유된 석면 함유 제품은 제조 - 수입 양도 - 제공 - 사용이 금지되었고, 이후 석면 제품 사용 의 금지조치가 더 강화되어 2009년부터는 모든 석면제 품의 사용(제조수입 포함)을 전면 금지하는 조치가 내 려지게 되었다. ${ }^{12)}$

최근 국내의 보일러 설치 및 배관작업(boilermaker)을 약 30년 정도 한 후 흉막 악성 중피종이 수리조선업 근 로자의 석면에 의한 직업성 폐암 증례를 보고하였다. ${ }^{13)}$ 우리나라의 경우 석면에 의한 근로자의 건강장해 위
험은 매우 높은 편이나 이에 관한 역학적 실태조사는 물론 아직도 석면사업장에 대한 정확한 근로자의 노출 에 관한 조사가 지속적으로 이루어지지 않고 있는 실 정이다.

따라서 본 연구는 일부 수리조선소의 엔진수리, 배관 수리, 보일러수리 공정을 대상으로 공기중 석면농도를 측정하여 근로자들의 노출실태를 평가하여, 향후 진행 되는 근로자의 건강보호를 위한 적정한 작업환경관리 및 석면노출 방지대책 수립과 공기질 개선을 위한 기 초자료를 제공하는데 있다.

\section{II. 연구 방법}

\section{1. 연구 대상}

본 조사대상은 경남지역에 소재한 $\mathrm{A}$ 수리조선업체에 서 1970 1980년대 건조된 20,000톤급 선박의 보수수리 (엔진, 배관, 보일러 등)를 하면서 과거에 설치되었던 석 면제품을 해체제거시, 의심되는 소재를 채취하여 분석 한 결과 백석면을 함유하고 있었다.

본 연구의 목적과 취지에 대한 충분한 설명후 해체제 거 작업일정을 파악한 후, 조사내용을 설명하고 작업 인원수, 조사기간 및 측정지점을 선정하였으며, 석면해 체제거 작업자 27 명을 대상으로, 2007년 10월 1일부터 10 월 30 일까지 수행하였다.

\section{2. 연구 방법}

1) 시료채취 및 분석

공기 중 석면 시료채취는 미국국립산업안전보건연구 원(National Institute for Occupational Safety and Health ; NIOSH)의 공정시험법에 ${ }^{14)}$ 따라 Cellulose Ester Membrane(CEM) filter(pore size $0.8 \mu \mathrm{m}$, 직경 $25 \mathrm{~mm}$ )가 내장된 $50 \mathrm{~mm}$ 카울(cowl)이 장착된 카셋 (cassette)을 이용하였고, 개인시료 채취기(Personal air sampler)의 유량은 약 $1.7 \mathrm{l} / \mathrm{min}$ 으로 개인시료를 포집하 였으며, 유량보정기를 사용전 후에 각각 3 회씩 측정하 여 측정값을 평균하여 사용하였다.

공기 중 석면의 분석은 ${ }^{15)}$ 위상차현미경(Phase Contrast Microscopy, PCM)으로 분석하였다. 이 방법은 채취한 필터를 아세톤으로 투명화하고 트리아세틴으로 기포가 생기지 않도록 고정시킨 후, Walton-Beckett Graticule (1시야면적 $0.00785 \mathrm{~mm}^{2}$ )이 삽입된 위상차현미경을 사 용하여 400배 배율에서 'A' 섬유 계수법(섬유의 길이 $5 \mu \mathrm{m}$ 이상, 길이 대 지름의 비가 3:1이상의 섬유를 계 수)으로 석면섬유를 분석하며 100 개의 섬유가 계수될 때 까지 최소 20 개 이상 충분한 수의 시야를 계수하되, 
계수한 시야의 수가 100 개를 넘지 않도록 한다.

\section{3. 통계 처리}

통계 분석은 SPSS 13.0 프로그램을 이용하였다. 공기 중 석면농도는 Shapiro-Wilk Test 검정한 결과( $\mathrm{p}<0.05)$, 대수 정규 분포를 함에 따라 평균 섬유 수는 기하평균 과 기하표준편차로 나타내었으며, 집단 간 차의 유의성 여부를 알기 위하여 변수들의 비교는 ANOVA 검정을 실시하였다.

\section{III. 결과 및 고찰}

\section{1. 일반적 특성}

조사대상 27명 전원이 남자였으며, 연령분포는 평균 연령이 35.9세였으며, 30 40세가 18 명 (66.7\%)으로 가장 많았으며, 40 세 이상은 5 명 $(18.5 \%), 30$ 세 이하가 4 명 $(14.8 \%)$ 의 순이었다. 근무경력은 5 년 이하가 12 명 (44.4\%)로 가장 많았으며, $5 \sim 10$ 년은 11 명 $(40.7 \%), 10$ 년 이상 4 명 $(14.8 \%)$ 였으며, 평균 근무기간은 6.56 년 이 었다.

대상 근로자의 흡연력은 현재 담배를 피고 있는 사람 은 15 명 $(55.6 \%)$ 이었고, 비흡자는 12 명 $(44.4 \%)$ 로 담배를 피는 사람이 더 많았으며, 음주는 $80 \%$ 이상 있었다.

작업공정별로 배관수리 12 명 $(44.4 \%)$ 으로 가장 많았 으며, 보일러 및 기타 작업자가 8 명 $(29.6 \%)$, 엔진 정비 가 7명 (25.9\%) 순으로 조사되었다.

\section{2. 수리조선 작업장내의 공기중 석면(asbestos) 농도 평가}

일반적으로 작업환경중 유해물질의 농도분포는 정규 분포보다는 대수정규분포(lognormal distribution)에 가 까운 것으로 알려져 있다 ${ }^{10}$. Figure 1 는 대수누적분포 로 나타낸 것이다. 각각의 농도값은 작업시간 동안의
Table 1. General characteristics of study subjects

\begin{tabular}{cccc} 
& & (Unit : number (\%)) \\
\hline \hline Valiable & & $\begin{array}{c}\text { No. of } \\
\text { samples }\end{array}$ & $\begin{array}{c}\text { Percent } \\
(\%)\end{array}$ \\
\hline Sex & Male & 27 & 100.0 \\
& $<30$ & 4 & 14.8 \\
Age(years) & $30 \sim 40$ & 18 & 66.7 \\
& $40 \leq$ & 5 & 18.5 \\
Work duration & $<5$ & 12 & 44.4 \\
(years) & $5 \sim 10$ & 11 & 40.7 \\
& $10 \leq$ & 4 & 14.8 \\
Smoking & Smoker & 15 & 55.6 \\
(Current) & Nonsmoker & 12 & 44.4 \\
Alcohol drinking & Yes & 22 & 81.5 \\
(Current) & No & 5 & 18.5 \\
& Marine engine & 7 & 25.9 \\
Worke & Piping work & 12 & 44.4 \\
Process & Boiler \& the other & 8 & 29.6 \\
& Total & 27 & 100.0 \\
\hline
\end{tabular}

시간가중평균치(Time-Weighted Average, TWA)를 계 산하여 나타내었다.

조선소 석면해체제거 작업시 공기 중 기하평균 농도 는 $0.004 \mathrm{f} / \mathrm{cc}$ 였으며, 범위는 0.001 0.570 f/cc로 조사 되었으며, 우리나라 노동부 노출기준을 초과한 측정건 수는 4 건이었다.

공기중 석면 농도가 우리나라 노출기준 $0.1 \mathrm{f} / \mathrm{cc}$ 보다 2 배 이상 높은 공정은 배관을 수리하는 과정에서 3 건 이었으며, 일부 작업자는 고농도의 석면에 노출되고 있 었다.

공기중 석면 섬유 농도가 가장 높은 배관수리 공정은 $0.007 \mathrm{f} / \mathrm{cc}$, 범위는 0.001 0.57 f/cc였으며, 가장 낮은 보

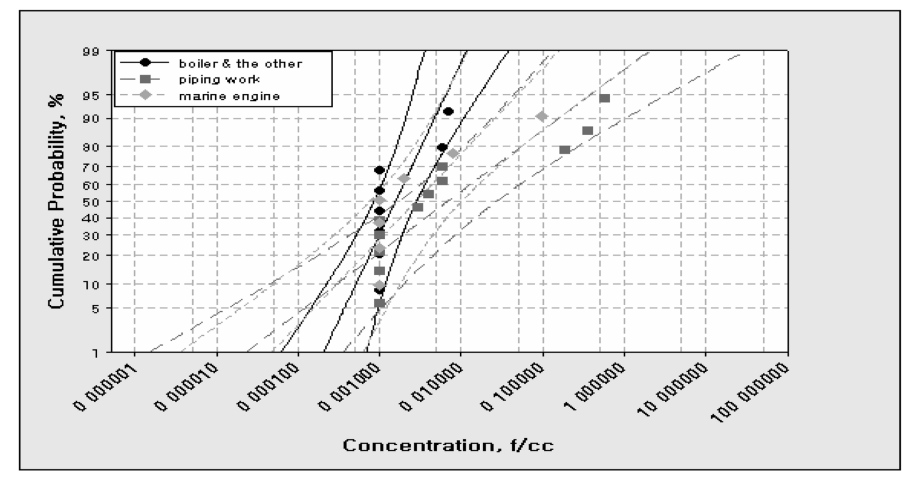

Fig. 1. Cumulative distribution of asbestos concentrations by workes process. 
Table 2. Mean of asbestos concentration in air different working sites

\begin{tabular}{lclccc}
\hline \hline \multirow{2}{*}{ Worke Process } & \multirow{2}{*}{ No. of samples } & \multicolumn{2}{c}{ Airborne asbestos concentration(f/cc) } & \multirow{2}{*}{$\begin{array}{c}\text { No.of samples } \\
\text { over KOEL }\end{array}$} \\
\cline { 3 - 5 } & & GM & Range & GSD & 1 \\
Marine engine & 7 & 0.003 & $0.001 \sim 0.100$ & 5.717 & 3 \\
Piping work & 12 & 0.007 & $0.001 \sim 0.570$ & 11.537 & - \\
Boiler \& the other & 8 & 0.002 & $0.001 \sim 0.007$ & 2.378 & 4 \\
Total & 27 & 0.004 & $0.001 \sim 0.570$ & 7.143 & 4 \\
\hline
\end{tabular}

GM : Geometric mean, GSD : Geometric standard deviation

'KOEL : Korean Occupational Exposure Limit

일러 및 기타 공정에서 $0.002 \mathrm{f} / \mathrm{cc}$, 범위는 $0.001 \sim 0.007$ $\mathrm{f} / \mathrm{cc}$ 였다(Table 2).

백도명 등은 1970 년대에 건조된 어선의 기관실 수리 작업이 진행되지 않은 공기중 석면농도는 0.01 0.02f/ $\mathrm{cc}$ 로 조사되었으며, 기관 및 배관의 노후된 석면을 자 르는 작업시 공기중 석면농도는 $6.3 \sim 7.8 \mathrm{f} / \mathrm{cc}$ 로, 본 연구 와는 차이를 보이고 있었다. ${ }^{17}$

우리나라의 노동부(2008)와 미국정부산업위생전문가 협 의회(American Conference of Governmental Lndustrial Hygienists, ACGIH, 1990)에서는 동일한 값을 허용기 준으로 설정하고 있으며, 노출기준 $0.1 \mathrm{f} / \mathrm{cc}$ 를 정하고 있다. ${ }^{10)}$

Table 3는 일반적인 특성에 따른 석면농도 분포는 연 령 분포는 30 대 미만에서 $0.007 \mathrm{f} / \mathrm{cc}$ 로 가장 농도가 높 았으며, 40 대 이상은 $0.002 \mathrm{f} / \mathrm{cc}$ 로 가장 낮았으나 유의 한 차이를 보이를 보이지 않았다. 수리조선 작업장 근 무력에서는 5 년 미만이 $0.006 \mathrm{f} / \mathrm{cc}$ 로 가장 높았으며, 5
년이상은 동일한 농도 분포를 보였다.

폐암의 가장 흔한 원인은 흡연이며, 석면 노출자에서 흡연을 하는 경우 폐암발생의 상승효과가 있는 것으로 알려져 있으며, ${ }^{18)}$ 석면에 노출된 근로자 둥 흡연자 집 단일 경우에 석면에 노출되지 않은 비흡연자 집단에 비 해 폐암으로 인한 사망률이 50 100배에 이른다. ${ }^{19)}$ 본 연구에서는 흡연자가 15 명으로 비흡연자 보다 많았으 며 평균농도는 $0.002 \mathrm{f} / \mathrm{cc}$ 로 였으며,음주는 $0.008 \mathrm{f} / \mathrm{cc}$ 로 현재 음주를 하지 않는 군에서 더 높았으나 통계적으 로는 유의한 차이를 보이지 않았다.

석면은 저농도에서도 장기간 노출시 중피종(mesothelioma)과 같은 치명적인 질병을 일으킬 수 있으므로, 가 능한 작업장의 석면농도를 최소한으로 유지하도록 최 선의 노력을 기울여야 할 것이다. 따라서 이 업종에 대 해서는 충분한 대책을 강구하여 석면의 위험으로부터 근로자를 보호하여야 하겠다.

Table 3. General characteristics of study subjects by airborne asbestos

\begin{tabular}{|c|c|c|c|c|c|}
\hline \multirow{2}{*}{ Valiable } & & \multirow{2}{*}{ No. of samples } & \multicolumn{2}{|c|}{ Airborne asbestos concentration (f/cc) } & \multirow{2}{*}{$\mathrm{p}$-value } \\
\hline & & & GM & GSD & \\
\hline \multirow{3}{*}{ Age(years) } & $<30$ & 4 & 0.007 & 10.251 & 0.71 \\
\hline & $30 \sim 40$ & 18 & 0.004 & 8.388 & \\
\hline & $40 \leq$ & 5 & 0.002 & 2.668 & \\
\hline \multirow{3}{*}{$\begin{array}{l}\text { Work duration } \\
\text { (years) }\end{array}$} & $<5$ & 12 & 0.006 & 12.455 & 0.23 \\
\hline & $5 \sim 10$ & 11 & 0.002 & 4.167 & \\
\hline & $10 \leq$ & 4 & 0.002 & 2.813 & \\
\hline \multirow{2}{*}{$\begin{array}{l}\text { Smoking } \\
\text { (Current) }\end{array}$} & Smoker & 15 & 0.002 & 3.816 & 0.08 \\
\hline & Non-smoker & 12 & 0.006 & 12.314 & \\
\hline \multirow{2}{*}{$\begin{array}{l}\text { Alcohol drinking } \\
\text { (Current) }\end{array}$} & Yes & 22 & 0.003 & 6.676 & 0.60 \\
\hline & No & 5 & 0.008 & 9.790 & \\
\hline \multirow{3}{*}{ Worke Process } & Marine engine & 7 & 0.003 & 5.717 & 0.23 \\
\hline & Piping work & 12 & 0.007 & 11.537 & \\
\hline & Boiler \& the other & 8 & 0.002 & 2.378 & \\
\hline
\end{tabular}




\section{IV. 결 론}

본 연구는 수리조선 작업장에 있어서 배관, 엔진, 보 일러 및 기차 수리작업시 발생되는 공기중 석면 농도 를 평가하기 위하여 2007년 10월부터 12월까지 공기중 석면 농도를 측정하여 얻는 결과는 다음과 같다.

1. 조사대상 27 명은 전원 남자였으며, 평균 연령은 35.9 세였으며, 30 40세가 18 명 $(66.7 \%)$ 으로 가장 많았으 며, 근무력은 5년 미만은 12 명 $(44.4 \%)$ 로 가장 많았으 며, 평균 근무기간은 6.6년이었다.

현재 흡연여부는 흡연자 15 명 (55.6\%)으로 더 많았으 며, 작업공정별로 배관수리 12 명 $(44.4 \%)$, 보일러 8 명 (29.6\%), 엔진 정비가 7명 (25.9\%) 순으로 조사되었다.

2. 수리조선 작업장내의 공기 중 석면(asbestos)의 기 하평균 농도는 $0.004 \mathrm{f} / \mathrm{cc}(0.001 \sim 0.570 \mathrm{f} / \mathrm{cc})$ 로 노출기 준 농도인 $0.1 \mathrm{f} / \mathrm{cc}$ 을 초과한 측정건수는 총 27 개 측정 치 중 $4(14.8 \%)$ 이었고, 2 배 이상 초과하는 시료는 3 개 로 나와 일부 근로자들는 고농도의 석면에 노출되고 있 었다.

3. 변수간 석면농도 분포는 연령별 분포는 30 대 미만 에서 $0.007 \mathrm{f} / \mathrm{cc}$ 로 가장 농도가 높았으며, 40 대 이상은 $0.002 \mathrm{f} / \mathrm{cc}$ 로 가장 낮았고, 근무경력는 5년미만이 0.006 $\mathrm{f} / \mathrm{cc}$ 로 가장 높았으며, 5년 이상은 동일한 농도 분포를 보였으나 변수간 유의한 차이를 보이지 않았다.

수리조선 작업자들의 비흡연자들의 석면 농도가 $0.006 \mathrm{f} / \mathrm{cc}$ 로 더 높았으며, 현재 음주를 하지 않는다는 군에서 $0.008 \mathrm{f} / \mathrm{cc}$ 로 더 높았으나, 통계적으로는 유의한 차이를 보이지 않았다.

따라서 이 업종에 대해서는 충분한 대책을 강구하여, 석면의 위험으로부터 근로자를 보호하여야 한다.

\section{참고문헌}

1. Woo, Y.S. : Growth of korean shipbuilding-allied industries and regional implications. Journal of the Korean Association of Regiona l Geogra, 9(1), 53-65, 2003.

2. Oh, J.S., Shin, Y.J., Lee, S.D. : Plan for vitalization of busan new port by activating ship repair industry. Korean Society of Marine Engineering, 31(6), 810817, 2007.

3. Kim, K. N., Kim, J. I., Lee, K. N., Jung, K. Y., Kim, J. Y. : Imaging findings among retired workers who were long-term exposed to asbestos. Korean society of occupational £II environmental medicine, 18(2),8793, 2006.

4. Ye, B.J., Kim, J.I., Lee, H.J., Kim, K.N., Jung, K.Y., Kim, J.Y., Yun, S.H. : The prevalence of asbestos exposure induced pleural thickening on chest radiograph in repairing shipyard workers. Korean society of occupational £II environmental medicine, 20(1), 9$14,2008$.

5. Ministry of Labor. Guideline of approval / permit system for removal of asbestos-containing fixtures. 15 54, 2007.

6. Ki, Y.H., Kim, J.M., Roh, Y.M., Chung, L.A., Kim, Y.S., Sim, S.H. : A survey for some asbestos containing products in korea, Korean Society of Environmental Health 34(1), 108-115, 2008.

7. Becklake, MR. : Asbestos-related diseases of the lung and other organs: their epidemiology and implications for clinical practice. American review of respiratory disease, 114, 187-227, 1976.

8. Park, D.Y., Paik, N.W. : Worker exposure to asbestos Fibers in asbestos slate manufacturing and asbestos textile industries. Korean Society of Environmental Health ,14(2), 13-27, 1988.

9. Timothy Driscoll, Deborah Imel Nelson, Kyle Steenland, James Lelgh, Marisol Concha-Barrientos, Marilyn Fingerhut, Annette Pruss-Ustun. : The global burden of diseases due to occupational carcinogens. American Journal of Industrial Medicine, 48(6), 419431, 2005.

10. Korea Asbestos Management Association. The $10^{\text {th }}$ professional asbestos agent fostering curriculum, 231345, 2008.

11. Official Journal of the European communities : Commission Directive 1999/77/EC adapting to technical progress for the sixth time Annex I to Council Directive 76/769/EEC relating to restrictions on the marketing and use of certain dangerous substances and preparations, 1999.

12. Ministry of Labor: About industrial health standard rule, 2007.

13. Yoon, D.Y., Kang, J.W., Lee, H.J., Kim, J.I., Son, J.E., Jung, K.Y., Kim, J.Y., Roh , M.S. : A case of lung cancer by long-term asbestos exposure. Korean Society of Occupational \& Environmental Medicine, 16(4), 499-504, 2004.

14. Naztional Institute for Occupational Safety and Health(NIOSH). Asbestos Fibers in Air, Method No. 7400, NIOSH Manual of Analytical Method, 3rd Edition, DHHS(NIOSH) Publication No. 84-100, Cincinnati, OH, 1989.

15. National Institute for Occupational Safety and Health (NIOSH). Manual of analytical methods, 4th Ed., asbestos and other fibers by PCM No. asbestos (bulk) by PLM No. 9002, 1994.

16. American Conference of Govermental Industrial Hygienists : Air Sampling Instruments for Evaluation of Atmospheric Contaminants, 7th Ed., ACGIH, 1989.

17. Paek, D.M., Paik, N.W., Choi, J.D., Son, M.A., Im, J.G., Lee, W.J., Moon, Y.H., Park, J.S., Choi, B.S.: Prevalence of asbestosis in Korean asbestos industry. Korean Society of Occupational \& Environmental 
Medicine, 7(1), 46-57, 1995.

18. Kamp DW. Srinivasan M. Weitzman SA. : Cigarette smoke and asbestos activate poly-ADP-ribose polymerase in alveolar epithelial cells. Journal Investing Medicine, 49(1), 68-76, 2001.
19. Last JM, Wallace RB. : Asbestos and other fibesrs. In: Maxcy-Rosenau-Last Public Health Preventive Medicine. 13th ed. Appleton \& Lange, East Norwalk, 343-64, 1992. 